\title{
EL MOVIMIENTO CONSTITUCIONALISTA EN CUSCO, 1809-1812
}

\section{THE CONSTITUTIONALIST MOVEMENT IN CUSCO, 1809-1812}

\author{
Margareth Najarro Espinoza \\ Universidad Nacional de San Antonio Abad del Cusco
}

SUMARIO:

\author{
I. LA CRISIS \\ II. LA ELECCION DE REPRESENTANTES ANTE LA JUNTA CENTRAL \\ III. LOS SUCESOS EN CUSCO: 1809 Y 1811 \\ 3.1. La conspiración de Huaro: 1809 \\ 3.2. Felipe Rocha: 1809 \\ 3.3. Martina de la Paz Chiguantopa Coronilla Ynga: 1810 \\ 3.4. Más tensiones: Agustín Chacón y Becerra versus Pedro Antonio \\ Cernadas \\ IV. LA LLEGADA DE LA CONSTITUCIÓN AL CUSCO \\ 4.1. Las tensiones \\ 4.2. "Asonada y tumulto": la elección del 7 de febrero de 1813 \\ 4.3. Las estrategias de la Audiencia: Pedro López de Segovia \\ 4.4. El exilio de los líderes constitucionalistas
}

\section{Resumen:}

Este trabajo busca examinar los sucesos ocurridos en Cusco en el contexto de la crisis política provocada por la invasión napoleónica a España. Se trata de entender, la etapa previa al arribo de la Constitución de 1812 al Cusco, para examinar la situación que se vivió en ese periodo de cambios trascendentales. Finalmente, se busca analizar el impacto que tuvo la Constitución doceañista al interior de la sociedad cusqueña, los conflictos que generó y la forma en que distintos actores políticos confluyeron en un mismo espacio y en un contexto de profundas transformaciones politicas y sociales.

\begin{abstract}
:
This paper seeks to examine the events that occurred in Cusco in the context of the political crisis caused by de Napoleonic invasion of Spain. It is about understanding the stage prior to the arrival of the Constitution of 1812 in Cusco, to examine the situation that was experienced in Cusco in this stage of momentous changes. Finally, it seeks to analyze the impact that the Twelve-year Constitution had within Cusco society, the conflicts it generated and the way in which different political actors converged in the same space and in a context of profound political and social transformations.
\end{abstract}

Palabras clave:

Cusco, Constitución, constitucionalismo, conflictos y elecciones

\section{Key Words:}

Cusco, Constitution, constitutionalism, conflicts and elections 


\section{LA CRISIS}

La invasión napoleónica a España en 1808 provocó un cataclismo político y social que tuvo profundas repercusiones en España y América. Ante ese suceso, rápidamente se formaron las primeras Juntas de Gobierno americanas, y aunque estas tuvieron corta duración, lograron conmover el escenario político americano.

Los vertiginosos sucesos ocurridos en España van a tener gran impacto en Hispanoamérica y determinan una serie diversa de reacciones en cada lugar. De hecho, las noticias que llegan hacia América generan desconcierto por lo inédito de la situación y el rumbo de los acontecimientos se abren paso al fragor de cada suceso. Manuel Chust, considera tres momentos o fases. La primera, empieza entre julio y septiembre de 1808, cuando llegan las noticias sobre el motín del Escorial, la abdicación de Carlos IV, la destitución de Godoy y la proclamación de Fernando VII. La segunda fase, empieza entre abril y mayo de 1809, cuando llegan las noticias sobre la creación de la Junta Central, y sobre todo, cuando se difunde el decreto de enero de 1809, por el que se convoca a los espacios americanos a participar en el gobierno. La tercera fase, inicia entre mayo y junio de 1810 , cuando arriban las noticias sobre la disolución de la Junta Central y la creación de la Regencia y la convocatoria a Cortes del 14 de febrero de 1810.1 Cada uno de estos sucesos, tiene un impacto y un peso distinto en el espacio americano.

Bajo este esquema, los americanos se encontraban, momento a momento, ante un escenario inédito. Así, se vieron involucrados en procesos electorales nunca antes vistos, aunque eventualmente estos proceso no se cumplieron por la interferencia de las autoridades, como ocurrió en Cusco durante las primeras elecciones. Por ejemplo, los procesos electorales, como la elección de diputados a Cortes Ordinarias, diputados provinciales y autoridades municipales, no implicaron necesariamente cambios trascendentales en todas partes. En realidad, estos procesos eventualmente profundizaron las brechas existentes al interior de la sociedad colonial, y atizaron el miedo y la desconfianza, como ocurrió en Cusco debido a la intervención de los miembros de la Audiencia en las primeras elecciones para representantes, propiciando solo la participaron de españoles.

En esas circunstancias en el Cusco, la elección para diputados no tuvo mayor trascendencia ni implicó cambios sustantivos, debido al manejo que ejercieron los miembros de la Audiencia en este proceso electoral con el claro propósito de impedir los cambios que se suponía debian regir en este nuevo escenario. Esta habria sido una de las causas que originó el conflicto irreconciliable que enfrentó a constitucionalistas y absolutistas en el escenario cusqueño, lugar donde los conflictos, entre ambos bandos, fue de los más enconados.

\section{LA ELECCION DE REPRESENTANTES: 1809 y 1811}

La Junta Central otorgó por primera vez representación a los americanos, pero "en amplia inferioridad numérica frente a los españoles". ${ }^{2}$ El virreinato peruano debía enviar un representante, y para ello se tomó en consideración la orden de elección de representantes que se publicó en la metrópoli el 22 de enero de 1809. De esta

1 Manuel Chust (coordinador), 1808. La eclosión juntera en el mundo hispano, Fondo de Cultura Económica, México, 2007, p. 28.

2 Victor Peralta Ruiz, En defensa de la autoridad. Politica y cultura bajo el gobierno del virrey Abascal. Perú 1806-1816, Consejo Superior de Investigaciones Científicas Instituto de Historia, Madrid, 2002, p. 146. 
manera, un total de diez representantes fueron convocados por primera vez, Río de la Plata, Nueva Granada, Nueva España, Venezuela, Cuba, Chile, Perú, Puerto Rico, Guatemala y Filipinas. Esta convocatoria tuvo un significado trascendental porque "el nuevo centro de poder integraba en calidad de igualdad en la representación a los territorios y habitantes peninsulares y americanos. Trascendental también porque implicaba la asunción de un principio hasta aquí inédito y era que América, sus habitantes y sus territorios, dejaban de pertenecer a la corona, al rey, y pasaban a integrarse en el nuevo centro de poder de la monarquía."3

Sin embargo, a pesar de la disposición y voluntad de generar tales cambios trascendentales desde la península, estos propósitos eventualmente no se cumplieron, como ocurrió en Cusco. La disposición sobre la primera convocatoria para representantes llegó al espacio cusqueño en junio de 1809. Se hallaba entonces como oidor regente y presidente interino de la Audiencia, Manuel Pardo, quien se encargó de organizar esta elección con el firme propósito de elegir un representante de su entorno. En esa ocasión, se presentó una terna de 3 candidatos vinculados a la Audiencia: José de Portilla y Gálvez, Manuel Plácido Berriozabal y el mismo Pardo, todos españoles. ${ }^{4}$ No es difícil suponer que este procedimiento causó malestar y descontento en los criollos, sobre todo de los sectores medios que tenían acceso limitado a las instancias del poder y que seguramente aspiraban ser parte de los cambios trascendentales ocurridos en este nuevo escenario.

En estas circunstancias, se dieron nuevos sucesos en la metrópoli que trastocaron nuevamente el espacio americano. La disolución de la Junta Central, enero de 1810, y la creación de la Regencia que reorientaron los procesos políticos que se venían dando en la región americana. Ante esta situación, la Regencia convocó a nuevas elecciones y estableció las primeras Instrucciones para elecciones en América y Asia, pero con menos representantes americanos en relación a los hispanos. ${ }^{5}$ Esta desigualdad generó el descontento americano que percibió este hecho como un perjuicio. Por tanto, aunque se habia derogado el principio del Antiguo Régimen por el que los americanos no tenian representación porque eran considerados súbditos, la diferenciación numérica entre América y España motivó a ciertos sectores criollos a no reconocer la Regencia ni a las Cortes. ${ }^{6}$ La fractura se había producido. La Regencia promovió cambios trascendentales, al acelerar la convocatoria a Cortes "en una única Cámara y no por estamentos. Acontecimiento revolucionario, por cuanto ya no serán el privilegio estamental ni el poder del rey, las premisas fundamentales de la representación en Cortes, como en el Antiguo Régimen."7

El problema fue que ya se había producido el descontento frente a la diferencia numérica de representantes americanos. Otro aspecto a considerar es que las disposiciones de la Regencia no se cumplieron en ciertos lugares, como en Cusco. En la convocatoria hecha por la Regencia a Cortes, se determinó que todas las "cabezas

\footnotetext{
3 Manuel Chust e Ivana Frasquet, Las independencias en América, Catarata, Madrid, 2009, p. 28.

4 Víctor Peralta Ruíz, "Elecciones, Constitucionalismo y revolución en el Cuzco, 1809-1815, op. cit., p. 100.

${ }_{5}^{5}$ Manuel Chust e Ivana Frasquet, Las independencias en América, Catarata, Madrid, 2009, p. 35.

6 Ibíd. p. 36.

7 Ibíd. P. 38.
} 
de partido" tendrían un diputado, razón por la que el Cusco debía tener un representante, el cual se reuniría con los de España en Cádiz para redactar una Constitución. ${ }^{8}$ Ante esta novedad, nuevamente la Audiencia del Cusco interfirió en esta elección, a pesar de que era el Cabildo el que debía organizarla. Así, Pardo volvió a elaborar una terna, habiendo concurrido las mismas personas que habian asistido a la primera elección; en esta ocasión fue elegido Manuel Galeano, quien tampoco logró viajar a España por problemas de financiamiento. 9

La interferencia de la Audiencia en las primeras elecciones, seguramente estuvo movida por el "terror" que tenían ante los sucesos que se venían produciendo entre los "porteños revolucionarios" y las fuerzas realistas en el Alto Perú, como así lo hizo saber el presidente interino de la Audiencia del Cusco al virrey Abascal en abril de 1811.10

Al mes siguiente de esta elección, el 27 de septiembre de 1811, en sesión pública de Cortes, el diputado Morales Duárez, denunció la intervención del virrey Abascal en la elección de diputados a Cortes con el propósito de impedir el nombramiento de criollos; este hecho, según este diputado, habia provocado un escándalo en el Perú. ${ }^{11}$ Por la forma cómo se realizaron las dos primeras elecciones en el Cusco, es de suponer que el virrey Abascal y Pardo estuvieron de acuerdo para manejar tales elecciones e impedir la elección de criollos, como señala la denuncia hecha por el diputado Duárez. Este tipo de manejos, impidieron la introducción de los cambios promovidos desde la metrópoli hispana, y profundizaron las tensiones ya existentes entre criollos y españoles en Cusco.

\section{LOS SUCESOS EN CUSCO: 1809 Y 1811}

La injerencia del virrey Abascal en coordinación con la audiencia cusqueña, durante las primeras elecciones, fue manifiesta. La decisión de las autoridades hispanas de manejar las elecciones obedeció, con seguridad, a los antecedentes que tenía este espacio como zona rebelde. El levantamiento de 1780 dejó una secuela de miedo latente a un nuevo alzamiento de la población indigena. ${ }^{12}$ No en vano, en 1786, el intendente Mata Linares escribió que "perdido Cuzco, todo el reino se perdía, pues la sierra es el escudo de toda esta América."13

Asimismo, contribuyó a esta imagen rebelde del Cusco, la conspiración de 1805, dirigida por Gabriel Aguilar y Manuel Ubalde, criollos de clase media y provincianos, que habían planificado asaltar el cuartel, tomar la ciudad y expulsar a los españoles. La conspiración fue develada, y el 5 de diciembre de 1805, año en que ambos líderes

8 Víctor Peralta Ruiz, En defensa de la autoridad. Política y cultura bajo el gobierno del virrey Abascal. Perú 1806-1816, op. cit., p. 147-148.

9 Ibid.

10Luis Miguel Glave, "Cultura politica, participación indígena y redes de Comunicación en la crisis colonial. El virreinato peruano, 1809-1814, op. cit., p. 373.

11 Brian, Hamnett, Revolución y contrarrevolución en México y el Perú. Liberales, realistas y separatistas, 1800-1824, Fondo de Cultura Económica, México, 2012, p. 43.

12 Claudia Rosas, "El miedo a la revolución. Rumores y temores desatados por la Revolución Francesa en el Perú, 1790-1800”, en Claudia Rosas (editora), El miedo en el Perú siglos XVI al XX, Pontificia Universidad Católica del Perú, Lima, 2005, p. 139.

13 Charles Walker, De Tupac Amaru a Gamarra. Cusco y la formación del Perú republicano 1780-1814, CBC, Cuzco, 2004, p. 8. 
fueron ejecutados en la Plaza de Armas del Cusco, donde años antes había sido descuartizado Tupac Amaru. ${ }^{14}$ El recuerdo sobre esta conspiración estaba todavía fresco, y seguramente preocupaba al virrey y a los miembros españoles de la Audiencia del Cusco, el impacto que tendría en este espacio la nueva coyuntura provocada por la invasión napoleónica a España.

\subsection{La conspiración de Huaro: 1809}

La Conspiración de Huaro (Quispicanchi) ocurrida en 1809, nos aproxima a la coyuntura que se vivió en Cusco en este periodo de crisis política provocada por la invasión napoleónica a España. A partir de este caso, se visualiza la forma cómo se agudizó el resentimiento de la población nativa en relación a los peninsulares. Los pocos casos disponibles, que llegaron a convertirse en expedientes o que fueron preservados, como el caso de Huaro, nos aproximan a esta coyuntura.

Como ha señalado Walker, en una ciudad como Cusco, circulaban diversas versiones sobre los sucesos ocurridos en España y sobre el significado que este hecho tendría en la vida de los pobladores; las personas interpretaban estos cambios como una oportunidad para lograr relaciones más justas. ${ }^{15}$ Justamente, durante la conspiración de Huaro, Mariano Soria, un zapatero que además era integrante de la milicia en Quispicanchi, escuchó a unos indigenas relatar un plan de alzamiento que empezaría con el asesinato de un cacique no indigena. ${ }^{16}$ Este suceso expresa el descontento que generó en Cusco la proliferación de caciques no indígenas como consecuencia del movimiento de 1780, hecho que se produjo como parte del proceso de asedio contra la nobleza indígena. Asimismo, muestra que en una coyuntura como la que se vivía en 1809, surgieron las expresiones de descontento y los resentimientos de la población indígena, que eventualmente pensaba o deseaba organizar un alzamiento.

Los conspiradores de Huaro, habian urdido todo un plan de acción con miras a levantarse. El proyecto incluyó varias acciones de ataque y defensa, al extremos de haber planeado el incendio de casas y el derrumbe de construcciones para detener y demorar a las tropas; también planificaron el saqueo de casas y la incautación de los tributos, "respecto de haber muerto ya el rey"; lo más sorprendente fue, la afirmación de que tenían el respaldo en toda la región sur andina y "vínculos directos con los rebeldes de Tupac Amaru"; y que desde Quiquijana hasta Puno estaba proyectada esta sublevación, en la que participaria, Mariano Bastidas, vecino de Tungasuca y hermano de Micaela Bastidas, esposa de José Gabriel Túpac Amaru. ${ }^{17 E s ~ i n t e r e s a n t e ~}$ constatar que en este período de crisis política, se activó el descontento y la posibilidad de un alzamiento, en cuyo escenario surgió nuevamente el fantasma de Tupac Amaru.

\subsection{Caso Felipe Rocha: 1809}

${ }^{14}$ Alberto Flores Galindo, Buscando un inca: identidad y utopia en los Andes, Instituto de Apoyo Agrario, Lima, 1988, p. 177 y 178.

15 Charles Walker, De Tupac Amaru a Gamarra. Cusco y la formación del Perú republicano 1780-1814, op. cit., p. 121.

16 Ibíd,, p. 120.

17 Ibíd. 
Otro caso importante, ocurrido en 1809, nos aproxima a otro escenario que se vivió en Cusco en este periodo. El primer dia de noviembre de 1809 se inició una causa judicial en la Audiencia cusqueña contra Felipe Rocha, natural de La Paz y estudiante en el colegio San Antonio Abad del Cusco. Este personaje era cuñado de Pedro Rodríguez, uno de los principales activistas de la Junta Tuitiva de La Paz. 18 Aparentemente, el establecimiento de esta Junta, despertó la desconfianza de las autoridades reales sobre los residentes altoperuanos en Cusco, quienes fueron considerados como sospechosos. Este hecho habría movido a las autoridades a realizar un seguimiento discreto de estos residentes, y como consecuencia de esto llegaron a confiscar una carta que escribió el mencionado Rocha a su cuñado Pedro Rodríguez, donde le expresaba que se encontraba asustado porque temía:

“[...] se ejecute alguna violencia con los pazeños y especial conmigo que estoy remirado [...] la adjunta papeleta instruirá a usted de noticias [...] abiseme usted en que está ocupado y quienes son los que conforman la junta representativa. Aquí se ha promulgado que Murillo le ha pasado un oficio a Goyeneche rindiéndole la ciudad y las armas, que se ha destruido la junta [...] este oficio se ha leído donde Cernadas $[\ldots]^{19}$

Ante esta evidencia, que daba cuenta de cómo circulaba la información en Cusco sobre los sucesos en La Paz, Felipe Rocha fue citado por el intendente Pardo a dar su declaración, ocasión en la que reconoció que la carta era suya, aunque negó tener algún vínculo con la Junta de La Paz. Después de una investigación, el 2 de noviembre de 1809, Pardo ordenó la prisión y embargo de los bienes del acusado. Lo que aparentemente precipitó la condena de Rocha, fue una comunicación "reservada" enviada por Goyeneche, donde éste señaló que la carta de Rocha era "sospechosa como perjudicial" y sugirió que "a la brevedad" fuese citado, tomando las medidas pertinentes "para sofocar el estrago" que podría provocar "un individuo tan pernicioso".

En Cusco residian muchas personas provenientes del Alto Perú, que venían a estudiar debido al prestigio que tenían los centros académicos cusqueños. Se sabe, por ejemplo, que ciertos abogados, miembros de la Junta Tuitiva de la Paz, habían estudiado en la universidad del Cusco, como fue el caso de Gregorio García Lanza y Pedro Domingo Murillo, 20 principales promotores de la Junta. No fue casual, por tanto, que Felipe Rocha fuese uno de los que esparció los sucesos paceños en Cusco, cumpliendo los planes de Murillo de propagar los eventos de La Paz en las provincias de Cusco, Arequipa, Puno y Cochabamba.21

18 Esta Junta fue una de las primeras en América, y realizó una serie de acciones y cambios en su breve período de existencia: reunió milicias, designó autoridades, acopió armamento; pero no logró partidarios en otros lugares del territorio, Véase Manuel Chust e Ivana Frasquet, "La génesis de las independencias. La complejidad de un proceso histórico de dimensiones universales", en Manuel Chust e Ivana Frasquet (eds.), La patria no se hizo sola. Las revoluciones de las independencias iberoamericanas, Sílex, Madrid, 2012, p. 46.

19 ARC. Real Audiencia, Causas Ordinarias. Leg. 65: 1809.

20 Scarlett O`Phelan Godoy, "El Perú de Abascal: entre la Constitución de Cádiz, la Lima fidelista y la reformulación del espacio virreinal, en Manuel Chust e Ivana Frasquet (eds.), La patria no se hizo sola. Las revoluciones de las independencias iberoamericanas, Sílex, Madrid, 2012, p. 219.

21 Scarlett O־Phelan Godoy, El mito de la "independencia concedida": los programas politicos del siglo XVIII y del temprano XIX en el Perú y Alto Perú (1730-1814), en Alberto Flores Galindo (Comp.), Independencia y revolución (1780-1840), Instituto Nacional de Cultura, Lima, 1987, p. 
A raíz de las investigaciones realizadas por la Audiencia, en relación a este caso, los catedráticos del colegio fueron citados a declarar, y a partir de sus afirmaciones se sabe que en el claustro antoniano circularon las noticias sobre los sucesos en Quito y La Paz. En las investigaciones realizadas, el padre Ramón Málaga, declaró que cuando entró casualmente a la celda del padre Anselmo Villanueva, éste se encontraba leyendo con otros una proclama. Otro hecho a destacar de las investigaciones realizadas sobre este caso, fue la constatación de que los catedráticos dieron las mejores referencias de Rocha, probablemente con la finalidad de aminorar su sentencia, sin embargo, esto no logró disuadir a los miembros de la Audiencia sobre la culpabilidad de éste. Rocha, finalmente, fue condenado a dos años de destierro a la ciudad de La Plata.

Este caso, muestra el ambiente de agitación que se vivió en Cusco en esos años a influjo de la formación de las primeras juntas de gobierno americanas. Por otro lado, cabe señalar que el expediente contra Rocha, no se circunscribió solo a los sucesos de La Paz, también se hizo referencia a la junta de gobierno de Quito. De hecho, en la primera página de este expediente, se adjuntó una proclama del marqués de Selva Alegre a los habitantes de Quito, donde se informaba sobre los sucesos acaecidos durante la formación de esta Junta: la destitución y encarcelamiento del presidente de la Audiencia de Quito, del obispo y otros magistrados. También se dio a conocer la creación de la "primera junta suprema soberana", cuyo presidente era el marqués de Selva Alegre.

Otro aspecto relevante de la proclama en cuestión, fue la alusión que se hizo del presidente depuesto de la Audiencia de Quito -Manuel Ruiz de Castilla-22 que también había sido presidente de la Audiencia de Cusco. En la referida proclama se señaló que los rebeldes, es decir los miembros de la Junta, le habian "arrostrado" a Manuel Ruiz de Castilla, la decapitación de Aguilar y Ubalde, "protestando vengar en su persona esa sangre inocente" 23. Esta alusión que se hizo de la conspiración de 1805, resulta interesante porque muestra el conocimiento que se tenía en otros espacios sobre este movimiento, y el hecho de que los miembros de esta Junta, señalasen que vengarian la muerte de Aguilar y Ubalde, expresó una identificación con este suceso y con sus líderes.

Este expediente resulta también importante porque muestra la forma en que circularon las noticias sobre las primeras juntas de gobierno americanas en el Cusco. Asimismo, la alusión que se hizo a los líderes de la Conspiración del Cusco de 1805, Aguilar y Ubalde, en el contexto de la Junta de Gobierno en Quito es interesante. Nótese que este mismo año, 1809, durante la conspiración de Huaro, citada lineas arriba, los indigenas rememoraron a Tupac Amaru, mientras que los

154 Cit. A Manuel M. Pinto, La revolución de la Intendencia de La Paz (1800-1810). (La Paz, 1945), pp. 303-304.

22 Manuel Ruiz Urries de Castilla, conde de Ruiz de Castilla, se trasladó al virreinato peruano, donde ocupó el cargo de Corregidor de Paruro y coronel de milicias durante el levantamiento de Tupac Amaru, en cuyo contexto recibió el grado de coronel de Ejército en 1783. Este año el virrey Jáuregui le nombró gobernador militar del Cusco y años después, en 1788, fue nombrado intendente de Huancavelica. En 1792 fue ascendido a brigadier y al año siguiente ascendió a comandante general de armas del Cusco y presidente de la Audiencia, cargo que ocupó de 1793 hasta 1806. Es decir que durante su gobierno se produjo la conspiración del Cusco de 1805. Posteriormente, en 1807, fue nombrado presidente de la Audiencia de Quito y el 10 de agosto de 1809 fue despuesto durante la creación de la junta de gobierno de Quito. Véase Real Academia de la Historia http:/ / dbe.rah.es/biografias / 16092/manuel-ruiz-de-urries-y-castilla

23 ARC. Real Audiencia, Causas Ordinarias. Leg. 65: 1809. 
miembros de la Junta en Quito, rememoraron a los líderes criollos de la conspiración de 1805 .

\subsection{Martina de La Paz Chiguantopa Coronilla Ynga: 1810}

El año de 1810, se produjo otro suceso de particular importancia. Este año, Martina de la Paz Coronilla Ynga, ${ }^{24}$ cacica de 9 ayllus en el pueblo de Colquepata, Tono y Toayma (Paucartambo), inició un expediente judicial junto a un grupo de autoridades, entre los que se encontraban alcaldes, regidores, segundas, recaudadores de tributos y principales del lugar, todos los cuales sumaban 46 autoridades 25 .

Esta cacica, se colocó a la cabeza de este numeroso grupo de autoridades locales, y otorgó poder a Joseph Agustín Guamantupa, protector general de naturales, para interponer una "querella" en la Audiencia del Cusco contra Isidro Lezama y sus "socios", vecinos del partido de Paucartambo, por "el grave y atros agravio" inferido en la plaza pública, a los otorgantes y a todo el pueblo de Colquepata, "suponiendo que querian sublebarse". En este litigio, la cacica y las autoridades mencionadas, solicitaron la inhibición de la jurisdicción del subdelegado de Paucartambo y que, en remplazo de éste, se les nombrase juez en la jurisdicción de Calca. Como sustento de esta petición, alegaron la "mala voluntad" que les tenían los vecinos españoles de Paucartambo, a quienes los subdelegados prestaban mayor atención.

A partir de este caso se observa una polarización entre indígenas y españoles, y una mayor disposición de la población indigena y sus autoridades a confrontar a los españoles. Esta conducta, de todas maneras, fue alentada al amparo del nuevo contexto de crisis política y vacío de poder provocado por la invasión napoleónica a España, y por la formación de las primeras juntas de gobierno en Quito y La Paz.

\subsection{Más tensiones: Agustín Chacón y Becerra versus Pedro Antonio Cernadas}

El año de 1811, se produjo un conflicto en Cusco entre dos personas importantes de la ciudad. Se trataba del escribano Agustín Chacón y Becerra 26 y del regente de la Audiencia, Pedro Antonio Cernadas;27 ambas personalidades tenian un lugar central en la ciudad. Chacón y Becerra fue uno de los escribanos más importantes del Cusco y tenía con una amplia red social debido a su condición de escribano. ${ }^{28}$ Mientras que

24 Martina era hija del famoso cacique principal y gobernadora de 9 ayllus en Colquepata (Paucartambo);obtuvo el cacicazgo en Huayllabamba a través de su esposa Josefa Landevisnay. Este cacique fue descendiente de la Casa de Lloque Yupanqui y llegó a ser uno de los Veinticuatro Electores y fue electo alférez real en 1739. Actualmente, en el Museo Inca de la Universidad Nacional San Antonio Abad del Cusco, conserva un lienzo de tamaño natural perteneciente a este cacique, quien mandó a pintar este retrato para dejar constancia de su elección como alférez real. Véase Margareth Najarro, "Del cacicazgo provincial al alferazgo de los veinticuatro electores del Cusco: don Marcos Chiguantopa Coronilla Ynga”, Revista Histórica, 2010.

25 ARC. Prot. Not. Mariano Meléndez Páez, Prot. 184: 1812-1813, fs. 526 y ss.

26 En su testamento, Agustín Chacón y Becerra aparece consignado con el pomposo nombre de José Agustín Chacón de Luna Arvisa Uribiarte Bezerra Perez Ladrón de Guevara Cavesa de Vaca y Giral.

27 Este personaje español, era natural de Galicia y pertenecía a la Orden de Carlos III y de Isabel La Católica. Fue también Oidor de la Audiencia de Charcas, con cuyo empleo pasó al Cusco. Estuvo casado con Juana Rivero y en segundas nupcias con Eulalia de la Cámara. Véase Manuel de Mendiburu. Diccionario histórico biográfico.

28 El escribano, Chacón y Becerra, tenía una importante trayectoria como escribano de la ciudad, había llegado a ser notario público, mayor de gobernación, guerra e intendencia y real 
Cernadas era una autoridad importante y de mayor jerarquía, en su condición de español y miembro de la Audiencia, pero a nivel local no tenía el caudal social del que gozaba el escribano Chacón y Becerra. Cernadas llegó al Cusco a raíz de su nombramiento como miembro de la Audiencia, mientras que Chacón y Becerra había nacido en Cusco.

El 24 de junio de 1811, Agustín Chacón y Becerra, otorgó poder a tres personas para interponer "queja y agravio" por las injurias y "muchísimos daños y perjuicios" ocasionados a su persona por Pedro Antonio Cernadas, regente y presidente interino de la Audiencia. Chacón y Becerra, expresó airado que Cernadas le había ocasionado "daños irreparables" en agravio de su honor y el de su familia, por lo que solicitó la suspensión de todo juicio a iniciativa de éste en contra de su "buena reputación, nombre y opinión y fama". 29

El motivo del pleito inició porque Cernadas había acusado de traidores al escribano Chacón y Becerra y a su hijo. Esta acusación, se originó debido a la interceptación de una carta en marzo de 1811, en la que un tal Salvador Tossi, incitaba a Castelli a apresurar su venida al Cusco. Después de una serie de indagaciones, se determinó que Salvador Tossi, era el seudónimo del hijo de Chacón y Becerra. Este hecho motivó la denuncia de Cernadas contra Mariano Chacón y Becerra, pero no se entiende por qué incluyó en esta denuncia a su padre. 30

El anónimo en cuestión, había llegado a manos de un teniente cusqueño apellidado Armentia, y fue remitido desde Zepita por el comandante del ejército a Cernadas. En dicho anónimo, el remitente se presentó como "uno de los hijos 'de la antigua corte de los incas" que denunciaba los "abusos de las autoridades y las arbitrariedades de los 'extranjeros' contra los vecinos honrados y pidió que acelerara su marcha, que sería bien recibido en esta capital ". 31

Finalmente, a raíz de estos sucesos, Mariano Chacón y Becerra, fue exiliado a Lima, al Oratorio San Felipe Neri, y su padre lejos de mostrarse agradecido con Cernadas, se mantuvo "más altanero y orgulloso" contra éste. ${ }^{32}$ Este conflicto entre ambos personajes, muestra el descontento latente de cierto sector de criollos contra los españoles, que ante esta nueva coyuntura se habria profundizado. De hecho, en este periodo se observa, de otro lado, una mayor aprehensión de los miembros de la Audiencia sobre la población cusqueña, especialmente sobre los criollos. El mismo, Manuel Pardo, expresó que, desde la llegada de las noticias sobre la formación de las Juntas en España, "hubo una marcada declinación en el respeto a las autoridades establecidas", al punto que los criollos cusqueños "querian formar su propia junta".33

\section{Llegada de la Constitución al Cusco}

hacienda y escribano interino del Cabildo. ARC. Prot. Not. Agustín Chacón y Becerra, Prot. 65: 1806-1815, f. 384 y ss.

29 ARC. Prot. Not. Agustín Chacón y Becerra, Prot. 65: 1806-1815, fs. 440 y ss.

30 Antonio Eguiguren, Hojas para la historia de la emancipación del Perú. Tomo III, Lima, 1967, p. 187 y ss.

${ }^{31}$ Luis Miguel Glave, "Cultura politica, participación indígena y redes de Comunicación en la crisis colonial. El virreinato peruano, 1809-1814, op. Cit., p. 374.

32 Ibíd.

33 John Fisher, Gobierno y Sociedad en el Perú colonial. El régimen de las intendencias: $1784-$ 1814, op. cit. p. 243. 
El primero de enero de 1812 se realizó en Cusco la última elección del cabildo de acuerdo al sistema antiguo. Para esta elección, tres aspirantes, sorteados con anuencia de la Audiencia se presentaron, y salió electo, como alcalde de primera elección, Fabian Rosas. ${ }^{34 E s t e ~ a l c a l d e ~ r e c i b i o ́ ~ a l ~ n u e v o ~ p r e s i d e n t e ~ i n t e r i n o ~ d e ~}$ Gobierno, Mateo Pumacahua, en septiembre de 1812. Este nombramiento se habría producido para contener al movimiento constitucionalista que se había gestado en Cusco y ante la situación de tensión que se vivió desde 1809. Muy pronto, Pumacahua notó que ya había un "ambiente de tensión en la ciudad", hecho que informó al virrey, señalando que "algunos abogados habían circulado el rumor de que el virrey estaba dilatando la llegada de la Constitución". En este informe, Pumacahua, denunció a Rafael Ramírez de Arellano como el líder de un grupo de "revoltosos" descontentos del absolutismo. 35

La Constitución llegó al Cusco el 9 de diciembre de 1812, para esta fecha ya había un movimiento plenamente organizado, que esperaban con gran expectativa la llegada y aplicación de este nuevo cuerpo legal. Para este bloque de personas, la Constitución lo era todo, era el instrumento que les daba la posibilidad de ser "ciudadanos iguales" en relación a los españoles, pero también en relación a los criollos más encumbrados, que siempre habian monopolizado todos los cargos por su preminencia social y económica. Por tanto, este grupo de defensores de la Constitución, habría estado conformado por criollos de sectores medios, dispuestos a todo para hacer cumplir los preceptos constitucionales y poner en marcha las elecciones que les permitirian tener un papel protagónico.

En medio de esta efervescencia social, provocada por el arribo de la Constitución, los miembros del constitucionalismo, construyeron y dieron forma a un nuevo actor, el pueblo. Este nuevo protagonista, empezó a tomar cuerpo en el discurso, las arengas y proclamas de los constitucionalistas, que fueron los que diseñaron la imagen de este nuevo actor, el cual fue representado como una "voz general" que tenía "voz viva" a través de la Constitución. Asimismo, los constitucionalistas se auto proclamaron representantes y voceros de este nuevo actor político. Y ¿quiénes eran estos constitucionalistas? Los miembros activos del constitucionalismo eran principalmente abogados, que el día de la jura de la Constitución se hicieron visibles a través de la denominación de "ilustre cuerpo de abogados", entre los que destacó principalmente, Rafael Ramírez de Arellano. Este grupo de abogados estuvo compuesto por criollos de sectores medios y mestizos. ${ }^{36}$

\section{"Ilustre cuerpo de abogados"}

\begin{tabular}{|l|}
\hline Dr. D Miguel Vargas \\
Dr. D. Juan Corbacho \\
Dr. D. Nolberto Torres de la Cámara \\
Dr. D. Pedro Miguel Urbina \\
Dr. D. Rafael Ramirez de Arellano \\
Dr. D. Toribio Salas \\
Dr. D. Antonio Rodríguez \\
Lic. D. Francisco Sotomayor y Galdós
\end{tabular}

34 Víctor Peralta Ruíz, "Elecciones, Constitucionalismo y revolución en el Cuzco, 1809-1815, op. cit., p. 105. Este fue el último acto eleccionario en el que la Audiencia pudo influir.

35 Víctor Peralta Ruíz, "Elecciones, Constitucionalismo y revolución en el Cuzco, 1809-1815, op. cit., p. 106.

36 Ibíd. 


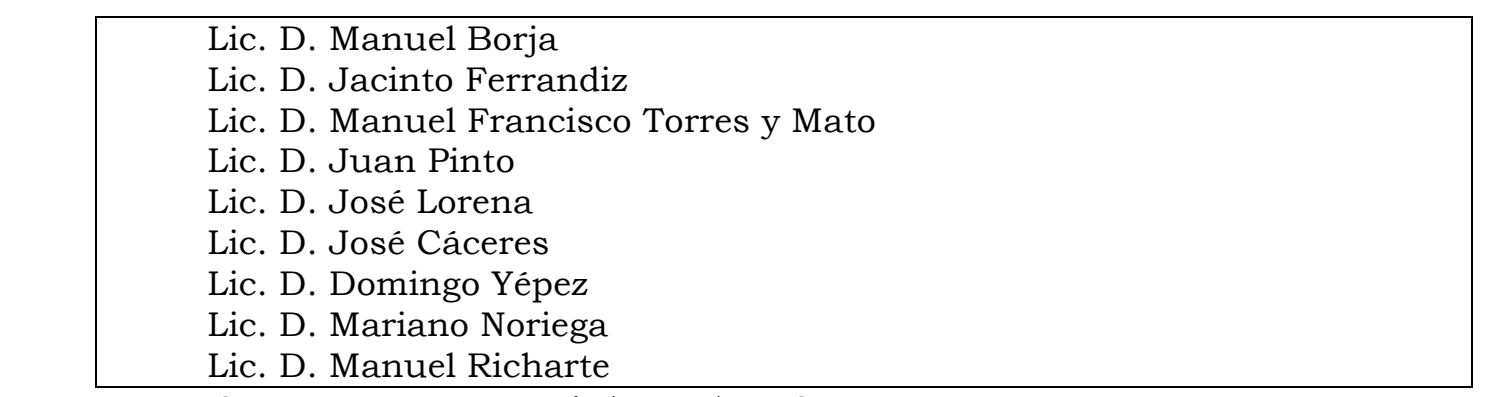

Fuente: CDIP, tomo III, vol. 7, p. 7 y 8.

Estos abogados se constituyeron en el bastión del movimiento constitucionalista cusqueño, y representaban a los sectores medios de la sociedad mestiza y criolla. Estos ciudadanos, fueron los que transfirieron, en el discurso, la soberanía al pueblo, y se auto nominaron en voceros de la voluntad popular.

\subsection{Las tensiones}

La gran expectativa que generó en Cusco la llegada de la Constitución, provocó los primeros enfrentamientos entre la Audiencia y el constitucionalismo. Una de las primeras fricciones entre ambos grupos se produjo desde antes de la llegada de la Constitución; los constitucionalistas, percibieron que se demoraba mucho en llegar desde Lima, y esto generó gran malestar: "cuanto más se demoraba en la capital de Lima sus ejemplares, tanto más se encendía el deseo de este generoso vecindario en ser el momento feliz de su regeneración política". 37

Según Rafael Ramírez de Arellano, ni bien llegó al Cusco la Constitución, Pumacahua, el escribano Chacón y Becerra y el regente de la Audiencia, Pardo, tenían el propósito de no cumplirla, y para ello "esparcieron" la voz de que este cuerpo legal era perjudicial para el pueblo. De esta manera, desde su llegada, la Constitución generó una conmoción social, entre quienes deseaban su inmediata aplicación y los que se oponían.

Los constitucionalistas estaban convencidos de que la Audiencia buscaba retrasar al máximo la aplicación de la Constitución con la finalidad de evitar la elección del nuevo Cabildo constitucional. Esto motivó a los constitucionalistas a denunciar al Cabildo vigente, por haberse coludido con el regente Pardo para mantenerse en sus cargos, con el pretexto de que no habia tiempo para la formación de padrones y juntas parroquiales. ${ }^{38}$ Ante esta denuncia, el Cabildo se reunió, el 11 de diciembre de 1812, con la finalidad de acordar los detalles de la publicación; en esta reunión se decidió que la juramentación se realizaría el 22 de diciembre, es decir 13 días despues de su arribo, con lo cual se confirmó la denuncia de los constitucionalistas que acusaban a la Audiencia de retrasar la aplicación de la Constitución.

Ante esta situación, el 14 de diciembre, Ramírez de Arellano y 32 personas se dirigieron a Pumacahua, expresando su descontento sobre el retraso de las acciones necesarias para llevar a cabo el nuevo proceso eleccionario. Asimismo, el 16 de diciembre de 1812, varios ciudadanos, 37 en total, se dirigieron nuevamente al presidente Pumacahua, expresando:

37 CDIP, tomo III, vol 7, p. 60. Informe del ayuntamiento del Cusco.

38 CDIP, tomo III, vol. 7, p. 60. 
“[...] los ciudadanos del Cusco que con la acción del pueblo y el vigor de la Constitución ya nos hemos expresado, volvemos a hablar ante usted [...] El juntar Cortes cada año, es el único medio legal de asegurar la observancia de la Constitución sin convulsiones, sin desacato a la autoridad y sin recurrir a medidas violentas que son precisas y aun inevitables cuando los males y vicios en la administración llegan a tomar cuerpo y envejecerse."39

Asimismo, se quejaron de la falta de diputado que les representase en Cortes, debido a que el Cabildo dilapidaba el dinero en refrescos, en lugar de orientarlos para los viáticos del diputado. A pesar de la presión ejercida por los constitucionalistas, el 23 de diciembre de 1812, se procedió finalmente a la jura de la Constitución, después de 14 dias de su llegada. A este acto, asistieron constitucionalistas y absolutistas.

Autoridades que juraron la Constitución de 1812

\begin{tabular}{|l|l|}
\hline Nombres & \multicolumn{1}{|c|}{ Cargos /institución } \\
\hline -Mateo García Pumacahua & -Presidente interino de la Audiencia \\
-Manuel Pardo Gonzales y Ribadeneira & -Regente \\
-Pedro Antonio Cernadas & -Oidor \\
-Pedro Mariano de Goyeneche & -Oidor \\
-Manuel de Vidaurre y Encalada & -Oidor \\
-Pedro López de Segovia & -Teniente asesor \\
\hline & \\
-Fabián Rozas & -Alcalde del primer voto \\
-Antonio Paredes & -Alcalde Provincial \\
-Marcos Fortón & -Juez subdelegado del Cercado \\
-Agustín Rosel & -Regidor \\
-Matias Martínez & -Regidor \\
-Diego Guerrero & -Regidor \\
-Dr. Rudecindo Tomás de Vera & -Regidor \\
\hline & \\
\hline -Dr. Miguel de Vargas & \\
-Dr. Juan Corvacho & \\
-Dr. Nolberto Torres de la Cámara & \\
-Lic. Pedro Miguel Urbina & \\
-Dr Rafael Ramirez de Arellano & \\
-Lic. Toribio Salas & \\
-Dr. Antonio Rodriguez & \\
-Lic. Francisco Sotomayor y Galdós & \\
-Lic. Manuel Borja & \\
-Lic. Francisco Ferrandiz de abogados" \\
-Lic. Manuel Francisco Torres y Mato \\
-Lic. Juan Pinto & \\
-Lic. José Lorena & \\
-Lic. José Cáceres & \\
-Lic. Domingo Yépez & \\
-Lic. Mariano Noriega & \\
-Lic. Manuel Richarte & \\
\hline & \\
\hline & \\
\hline
\end{tabular}

Fuente: CDIP, tomo III, vol. 7, p. 7 y 8.

39 CDIP, tomo III, vol. 7 , p. 3. 
Después de la jura de la Constitución, los enfrentamientos entre absolutistas y constitucionalistas continuaron. Los primeros, sindicaban a los constitucionalistas como "sediciosos" y "subversivos". Por su parte, Rafael Ramírez de Arellano, se avocó a escribir con la finalidad de mostrar las bondades y virtudes de la Constitución, con el claro propósito de ganar la "campaña electoral"40 que se avecinaba con miras a ganar las elecciones que elegirian a los miembros del cabildo constitucional. Con este firme propósito empezó a fraccionar un discurso liberal, moderno e inclusivo sobre las bondades de la Constitución doceañista. Destacó, por ejemplo, que gracias a este cuerpo legal habían sido elevados "a la clase de ciudadanos iguales", en relación a los "poderosos y nobles" que antes habian monopolizado los principales cargos. Asimismo, Ramírez de Arellano, tuvo la capacidad de elaborar un discurso liberal conveniente y convincente; desde esta prédica, el rey había dejado de ser "soberano absoluto" para convertirse en el "padre benéfico", cuyo único fin era "el bien y prosperidad de la patria".

Asimismo, Ramírez de Arellano, con la finalidad de ganar más adherentes para la causa constitucionalista, elaboró un discurso unificador en torno a la Constitución. Así, instaba a votar en las elecciones, por la "familia" y los "hermanos", y no, por los "desconocidos", esos "enemigos", "anticiudadanos" y "opuestos a la verdadera felicidad", refiriéndose a sus adversarios, los absolutistas. De esta manera, el discurso de Arellano se opuso a los españoles, como Pardo y Cernadas, que venian de fuera y ocupaban los puestos más altos, siendo ellos "desconocidos".

Los constitucionalistas, estuvieron dispuestos a todo a fin de poner en marcha los cambios propugnados en la Constitución. Como parte de su estrategia, elaboraron un meditado discurso de ataque contra quienes se atrevian a "profanar tan sagrada Ley". Así, desde este discurso, los absolutistas eran considerados como "anticiudadanos", "enemigos" y "opuestos a la justicia". 41 Como parte de esta estrategia, Ramírez de Arellano, elaboró un discurso inclusivo orientado a ganar a los sectores mayoritarios. Para ello, incorporó en sus proclamas a los sectores populares, refiriéndose a ellos, como "aquel humilde artesano", o "aquel retirado labrador".

\section{"Asonada y tumulto": las elecciones del 7 de febrero de 1813}

El 7 de febrero de 1813, se realizó la elección para elegir a los electores, quienes posteriormente, el 14 de febrero, en una reunión de electores debían elegir al primer Cabildo constitucional. Este proceso electoral, no se realizó con normalidad porque un día antes, el 6 de febrero, Pumacahua en coordinación con los oidores de la Audiencia, dispusieron el encarcelamiento de dos prominentes miembros del constitucionalismo, Rafael Ramírez de Arellano y Manuel Borja.42 El propósito estaba claro, se trataba de evitar la participación de ambos en las elecciones del día siguiente.

40 En Arequipa también se desarrolló una "campaña electoral” orientada a ganar las elecciones así como se hizo en Cusco, de manera que pronto se sintió una gran efevescencia social y política marcada por la llegada y aplicación de Constitución, pero también por ganar las elecciones bajo el nuevo marco constitucional. El término "campaña electoral" ha sido tomado de Wilber Alvarez "Deprimir la autoridad": la Constitución de Cádiz en las ciudades de Arequipa y Puno, 1812 $1814 "$,

http://www.academia.edu/3326218/_Deprimir_la_autoridad_la_Constitucion_de_Cadiz_en_las_ci udades_de_Arequipa_y_Puno_1812-1814

41 CDIP, tomo III, vol. 7, p. 24. Proclama de de Rafael Ramírez de Arellano "A los verdaderos hijos de la patria."

42 Ambos abogados eran los líderes más visibles del movimiento constitucional cusqueño, y firmaron el tercer memorial, de los 3 que se hicieron en 1812, exigiendo el cumplimiento de la 
Al inicio, las votaciones se realizaron normalmente, pero poco después, el proceso de votación fue interrumpido por un "tímido murmullo" que pronto se volvió "voz general" que preguntó "si podían votar por los abogados presos", a lo que Pumacahua respondió que no era posible porque estaban procesados criminalmente, razón por la que se encontraban "privados de voz activa y pasiva".43 Frente a este hecho, los constitucionalistas, que ya se habian organizado, protagonizaron un hecho sin precedentes, exigieron, a viva voz, la libertad de ambos abogados, y ante la negativa de Pumacahua, un grupo salió a liberarlos, en abierto desacato a la autoridad del presidente de la Audiencia. Otro grupo, se quedó para convencer a Pumacahua de formalizar la libertad de los dos abogados constitucionalistas; finalmente no tuvo más remedio que formalizar la libertad de ambos abogados, emitiendo las respectivas boletas de libertad, con lo cual su autoridad quedó disminuida. ${ }^{44}$ Consecuentemente, los abogados liberados lograron emitir su voto sin mayores incidentes ni oposición, hecho que significó un duro golpe para los miembros de la Audiencia que habian tramado el apresamiento de los mencionados constitucionalistas.

La turba que liberó a Ramírez y Borja, estuvo compuesta por los abogados constitucionalistas de quienes se decía contaban con la "docilidad del pueblo". Es decir que la mañana del 7 de febrero, participó en la asonada el llamado pueblo. A partir del informe de la Audiencia, es posible saber por quiénes estuvo compuesto ese conglomerado humano. Los miembros de la Audiencia señalaron a "dos mil hombres" compuesto por una "multitud de ciudadanos de todas las clases, la mayor parte de los que se llamaban de la plebe", "levantándose aun los indios de la plaza".

Ante esta situación, los miembros de la Audiencia arremetieron contra los constitucionalistas, acusaron a Ramírez de Arellano "y sus faccionarios" de repartir "millares de papeletas" con los nombres de los que debían ser elegidos, objetivo que habian alcanzado, "aun en el orden en que estaban en las papeletas".

La elección del 7 de febrero, demostró el poder del constitucionalismo cusqueño que hizo retroceder a la Audiencia en su pretensión de interferir, como ya lo habian hecho antes, en las elecciones. Los constitucionalistas estaban organizados y habian logrado convocar gran cantidad de adherentes que secundaban sus acciones, como se vio el 7 de febrero.

\subsection{La estrategia de la Audiencia: Pedro López de Segovia}

Después de las elecciones del 7 de febrero, los miembros de la Audiencia no estaban dispuestos a dejarse vencer. El 11 de febrero, Pardo y Cernadas, buscaron un acercamiento con Pedro López de Segovia, quien era teniente asesor de la Audiencia, pero al haber participado a favor de la liberación de los abogados constitucionalistas, el 7 de febrero, había sido desaforado de su cargo por Pumacahua. Este acercamiento, buscaba evitar que Pedro López, envíe un informe contrario a la Audiencia sobre los sucesos ocurridos el 7 de febrero.

Para esto, Pardo y Cernadas, se valieron de dos religiosos, Sebastián de La Paliza, rector del colegio de San Bernardo y de Isidro Dávila, religioso de la orden de San Francisco, quienes convencieron a López de Segovia con "amistosos ruegos" y

Constitución. Véase Víctor Peralta Ruíz, "Elecciones, Constitucionalismo y revolución en el Cuzco, 1809-1815, op. cit., p. 108.

43 CDIP, tomo III, vol. 7, p. 29.

${ }^{44}$ CDIP, tomo III, vol. 7, p. 78. 
"sacerdotales exortaciones" a reunirse con los miembros de la Audiencia. El teniente asesor, finalmente se allanó; acto seguido, los sacerdotes convencieron al escribano Chacón y Becerra, para lo mismo. Dicha reunión tuvo lugar en la casa de Pumacahua, ocasión en la que López de Segovia expresó que se sentía agraviado por Pumacahua, quien había actuado en "deshonor suyo" al retirarlo del cargo, a instancias del escribano Chacón y Becerra. Ante estas expresiones, Pardo y Cernadas, le dieron la razón a López de Segovia, y lo restituyeron en el cargo, desautorizando con ello a Pumacahua. Asimismo, para complacer al agraviado, decidieron separar temporalmente del cargo al escribano Chacón y Becerra, "bajo pretexto de enfermedad"; eso sí, la condición era que López no informase al virrey sobre los sucesos del 7 de febrero. 45

Con este arreglo, Pardo y Cernadas, lograban ganar tiempo y evitar un informe contrario al que pensaban enviar. Su objetivo era convencer al virrey de sacar a Ramírez de Arellano del Cusco para debilitar al constitucionalismo, y quien sabe derrotarlo. Sin embargo, este arreglo dejaba mal parados a Pumacahua y al escribano Chacón y Becerra, provocando el resentimiento de ambos. Este incidente tuvo que marcar el inicio del distanciamiento de Pumacahua y del escribano Chacón y Becerra de los miembros de la Audiencia.

En realidad, Pumacahua no mandaba en la Audiencia, Pardo y Cernadas eran los que tomaban las decisiones, hecho que era de dominio público. Justamente, su nombramiento como presidente de la Audiencia, no se había hecho para premiar su fidelismo exclusivamente. Su nombramiento bien pudo ser meditado por el virrey Abascal y los oidores de la Audiencia del Cusco con la finalidad de contener el movimiento constitucionalista, debido a la fama de cacique aguerrido y la capacidad que tenía Pumacahua de movilizar gente, como claramente demostró durante el levantamiento de 1780 .

Probablemente, el virrey Abascal pensó que un hombre como Pumacahua podría contener el avance del constitucionalismo, retrasando la aplicación de la Constitución. Pero no fue así, Pumacahua, cansado de estar en medio de las pugnas entre absolutistas y constitucionalistas, renunció al cargo y se retiró a Chinchero sin previo aviso, por lo que fue denunciado por el Cabildo por este "escandaloso abandonó". 46

Este hecho alejó definitivamente a este cacique fidelista del realismo; y probablemente, a esas alturas ya estuvo en contacto con los hermanos Angulo, líderes de la revolución de 1814. Asimismo, cabe mencionar que Agustín Chacón y Becerra, conocía desde mucho tiempo atrás a José Angulo, y que bien pudo ser este escribano quien convenció a Pumacahua de unirse al movimiento insurgente.

\subsection{Los conflictos continuaron}

Luego de la elección del primer cabildo constitucional, las pugnas entre absolutistas y constitucionalistas continuaron más que nunca. Según la versión de la Audiencia, ni bien se instaló en nuevo cabildo, empezó "la guerra" contra la Audiencia, "aspirando hacerse superior a ellas". Posteriormente, el 26 de febrero de 1813 , los electores de la parroquia matriz, elevaron un informe sobre los sucesos del 7 de febrero, donde acusaron a Pardo y Vidaurre, "autoridades togadas" de reprimir la aplicación de la Constitución:

45 CDIP, tomo III, vol. 7, p. 34.

46 Víctor Peralta Ruíz, "Elecciones, Constitucionalismo y revolución en el Cuzco, 1809-1815", op. cit., p. 115. 
[...] influyen al poderoso e intimidan al miserable para que con su condescendencia y servilidad suscriban su capricho: connaturalizados con la adoración e inciensos que exigen de estos moradores le hacen vivir en la inacción y apatía: cuando éstos quieren reclamar con alguna firmeza de carácter los derechos que la sabia y benéfica Constitución [...] les prodiga procuran aquellas deidades denigrarles con el negro título de insubordinados, soberbios y tumultuarios: Ensimismados Vuestro Regente Don Manuel Pardo funda su orgullo y engreimiento en que todos los hombres le aplaudan y adulen servilmente [..] el monstruoso e ingrato Don Manuel Vidaurre se ha dejado conocer por los papeles apócrifos y seductivos que ha dado a luz con el simulado título de la concordia $[\ldots]^{47}$

En este informe, los electores de la parroquia matriz, atribuyeron el estado de cosas a la ineptitud de Pumacahua, quien era dominado por los ministros y por el escribano Chacón y Becerra. Este último, según los electores, habría tramado la acusación contra Ramírez de Arellano y Borja por su adhesión a la Constitución, y por haber exigido el envio del diputado a la península. Asimismo, reiteraron la denuncia contra Pardo y Vidaurre, a quienes describieron como "pequeñas divinidades" y que la mayor parte de las convulsiones se habian provocado por:

"[...] el endiosamiento de los Oidores que a la sombra de la distancia han vejado y oprimido al vasallo y como en el dia se hallan estos habitantes escudados con la benéfica Constitución para usar libremente de su derecho y elevar sus quejas a las superioridades, se resienten aquellos Ministros porque terminaron las funciones de su despotismo."48

\subsection{El exilio de los líderes del constitucionalismo}

Meses despues de los sucesos del 7 de febrero, Pedro Antonio Cernadas, Manuel Vidaurre y Manuel Pardo, elevaron un informe ante el virrey contra Rafael Ramírez de Arellano. Finalmente, el 24 de diciembre de 1813, el virrey dispuso su salida junto a otros constitucionalistas rumbo a Lima, hecho que se efectivizó en enero de 1814. La decisión del virrey tuvo que ser precipitada por los primeros intentos del asalto al cuartel promovidos por los Angulo en octubre y noviembre de 1813. La audiencia emitió un informe subjetivo sobre estos sucesos, señalando que los constitucionalistas eran "los jefes principales" de aquellos disturbios y que José Angulo era "el revolucionario principal". Ante tales informes, el virrey dispuso el traslado de cuatro miembros del constitucionalismo a Lima, a quienes se acusó de desacato a la autoridad y alteración del orden público. 49

La salida de Ramírez de Arellano del Cusco y de otros miembros del constitucionalismo, provocó la renuncia del alcalde del primer voto y de un regidor,50 pero la estrategia de la Audiencia fue no aceptar tales renuncias. En los meses siguientes, se vivió en Cusco un ambiente enardecido, que obligó al virrey Abascal, a emitir una orden, disponiendo:

47 CDIP, tomo III, vol 7, p. 40 y ss.

48 CDIP, tomo III, vol. 7, p. 40 Informe de los electores de la parroquia matriz sobre los sucesos del 7 de febrero de 1813.

49 Víctor Peralta Ruíz, "Elecciones, Constitucionalismo y revolución en el Cuzco, 18091815", op. cit., p. 119

50 ARC. Libro de Cabildo, Leg. 30: 1813-1815, f. 93. 
“[...] la corrección de los eclesiásticos que en el pulpito o en conbersaciones privadas o en cualquier otra forma de palabra o por escrito, directa o indirectamente, osen denigrar a las Cortes o a sus individuos divulgando especies subersibas del orden y de la obediencia y sumicion [...].51

Meses después, estalló la revolución del Cusco, en agosto de 1814. Los constitucionalistas, no apoyaron al movimiento insurgente porque sus reivindicaciones estuvieron ancladas en la Constitución y no en la insurgencia.

\section{Conclusiones}

La formación de las primeras Juntas de Gobierno americanas en Quito y La Paz, surgidas en el contexto de la invasión napoleónica a España, tuvo pronta repercusión en Cusco. Las noticias sobre estos sucesos, circularon rápidamente en la ciudad para sorpresa de las autoridades y de la propia población. En este escenario, el claustro de San Antonio Abad, sirvió como espacio de difusión de las novedades políticas del momento. Este plantel, tenía una población estudiantil diversa, procedente de diferentes lugares, aspecto que contribuyó a la difusión de noticias al interior del claustro. Este fue el caso de Felipe Rocha, natural de La Paz y estudiante en el colegio San Antonio Abad del Cusco, era cuñado de Pedro Rodríguez, uno de los principales activistas de la Junta Tuitiva de La Paz. Rocha, fue el encargado de difundir las noticias de la Junta en La Paz en Cusco, y aparentemente, también fue el difusor de la Junta quiteña.

Los sucesos ocurridos en la metrópoli, y consecuentemente, la formación de las primeras juntas americanas en Quito y La Paz, provocaron en Cusco un clima de tensiones y conflictos. En este escenario convulso, eventualmente, resurgieron como referentes políticos los líderes de 1780 y 1805, quienes fueron reivindicados por los protagonistas de los disturbios.

Cuando la Constitución llegó al Cusco, el 9 de diciembre de 1812, ya había un grupo bien organizado que esperaban con gran expectativa la aplicación y cumplimiento de la Constitución. Este grupo de Constitucionalistas elaboraron un discurso inclusivo con la finalidad de lograr el apoyo de los sectores populares a la causa constitucionalista con miras al proceso eleccionario que pronto se realizaría para la elección del nuevo cabildo constitucional. El triunfo de los constitucionalistas en estas elecciones, expresan que la prédica constitucional impactó en un amplio sector de la sociedad cusqueña. Pero los miembros de la Audiencia tenían canales importantes para intentar impedir el avance del constitucionalismo en Cusco. En este sentido, uno de sus aliados fue el virrey Abascal, a quien informaban sesgadamente cada suceso ocurrido en Cusco. Uno de los últimos informes de la Audiencia, señalaba que los primeros intentos de los revolucionarios, de octubre y noviembre de 1813, habian sido promovidos por José Angulo y los miembros del Constitucionalismo. Este informe fue el que finalmente movió al virrey Abascal a tomar la decisión de exiliar a los principales constitucionalistas del Cusco, como lo venía pidiendo insistentemente la Audiencia. Este fue el primer golpe para el constitucionalismo, y el segundo, se produjo en agosto de 1814, cuando estalló la revolución de los Angulo y Pumacahua. El estallido de la insurgencia de 1814, impidió la continuidad del constitucionalismo, que se apagó lentamente por la fuerza de las armas insurgentes. Los constitucionalistas cusqueños no comulgaron con la insurgencia, eran monárquicos, aunque moderados y constitucionalistas. Esto último, sin embargo, no disminuye el papel trascendental que tuvieron en la transformación de la cultura política cusqueña de ese período.

51 ARC. Libro de Cabildo. Leg. 30: 1814-1815, fs. 167. 